\title{
Analysis of the Spatio-Temporal Variation of the Thermal Pattern of River Ganges in Proximity to Varanasi, India
}

\author{
Nilendu Das ${ }^{1} \cdot$ Rajarshi Bhattacharjee ${ }^{1} \cdot$ Abhinandan Choubey $^{1} \cdot$ Ashwani Kumar Agnihotri $^{1} \cdot$ \\ Anurag Ohri ${ }^{1} \cdot$ Shishir Gaur ${ }^{1}$
}

Received: 27 January 2021 / Accepted: 29 January 2022 / Published online: 24 February 2022

(C) Indian Society of Remote Sensing 2022

\begin{abstract}
The temperature of a river is a fundamental aspect of its water quality and has a bearing on its ecosystem to a greater extent. Therefore, in systematic planning for optimal stream monitoring programs involving the determination of location at monitoring stations, understanding this crucial thermal parameter is much desired. This would help to give an integrated scenario regarding physical, chemical, and biological processes occurring in the river ecosystem. Water quality parameters of the river such as dissolved oxygen, $\mathrm{pH}$, salinity get affected due to change in river thermal patterns. In this study, the Landsat-8 TIR sensor was used to study spatial and temporal variations of river temperature. Thermal bands of 23 cloudfree Landsat-8 images from June 2013 to November 2020 were processed to prepare thermal maps of a stretch of river Ganges at Varanasi, India. The work has been validated by in-situ temperature measurement with a portable thermal sensor having high accuracy $\left( \pm 0.1^{\circ} \mathrm{C}\right)$. A good correlation $\left(R^{2}=0.927\right.$ and RMSE $\left.=0.956\right)$ was observed between the sensor's estimated temperature and the in-situ temperature. The results exemplify that water surface temperature at confluence points was relatively higher due to the incoming effluents than the mid-river temperature. The 'confluence point 3 ' has the least relative temperature variation. The relative temperature variation has been more prominent for the month of February in comparison to June and November. Owing to the time series data availability and worldwide coverage of the Landsat- 8 satellite, the present work provides a promising strategy for studying the thermal patterns in other rivers.
\end{abstract}

Keywords Ganges · Landsat- 8 . Thermal sensor $\cdot$ Thermal pattern $\cdot$ Surface water temperature

Rajarshi Bhattacharjee

rajbhatt78645@gmail.com

Nilendu Das

dasnilendu2016@gmail.com

Abhinandan Choubey

choubey.civ18@itbhu.ac.in

Ashwani Kumar Agnihotri ashwanika.rs.civ15@itbhu.ac.in

Anurag Ohri

aohri.civ@iitbhu.ac.in

Shishir Gaur

shishirg.civ@iitbhu.ac.in

1 Department of Civil Engineering, Indian Institute of Technology (BHU), Varanasi 221005, India

\section{Introduction}

The temperature of the water is a vital physical parameter because it considerably affects the aquatic ecosystem of the river (Caissie, 2006; Ling et al., 2017; Smith, 2008; Wawrzyniak et al., 2012). Water quality parameters like dissolved oxygen (DO), $\mathrm{pH}$, salinity, and suspended sediment concentration depend on river water temperature. Numerous biological factors and conditions, such as stream profitability, are also emphatically connected to the water temperature of the rivers. It additionally impacts the rate of photosynthesis by green algae and aquatic plants and governs the overall health of flora and fauna in the river; further, it also influences the spatial allocation of the organisms (Bäckström et al., 2002; Crisp, 1990; Smith, 2008; Terzi \& Verep, 2011). The river continuum concept emphasises that the change in the temperature of the river can have an immense effect on the longitudinal distribution 
of aquatic plants and animals living in that fluvial environment (Vannote et al., 1980; Wawrzyniak et al., 2012). If the stream temperature rises above a specific threshold value, biological processes such as growth or reproduction, or even survival itself, are anticipated to decline or even perish (Eaton et al., 1995a, 1995b; Xin \& Kinouchi, 2013). Hence, stream temperature becomes an important factor of water quality, predominantly in those areas where endangered fish species are sensitive to water temperature flux (Handcock et al., 2006). According to Van't Hoff's theory, for every $10{ }^{\circ} \mathrm{C}$ rise in water temperature, the biological activity almost doubles (Caissie, 2006). The physical, chemical and biological properties of rivers are also affected by stream temperatures; it affects aquatic organisms' metabolic rates and life histories, the efficiency of chemical reactions, DO concentrations, and nutrient cycling. DO concentration additionally influences metabolic rates of amphibian life forms, predation hazard, and impact the creature behavior and fish network structures (Magoulick \& Kobza, 2003; Null et al., 2017; Poole \& Berman, 2001). DO immersion fixations have a reverse association with stream temperatures, such that with every increment in temperature, DO content in the water decreases. The temperature-subordinate solvency of oxygen demonstrates that the DO should be higher around the night when the temperature is lower and vice-versa. However, photosynthesis occurring in the daylight and respiration in numerous rivers perform a major role in turning around this pattern. River water quality impairments like warm watercourse temperatures and low DO concentrations also limit ecosystems and habitats (Loperfido et al., 2009; Null et al., 2017; Viswanathan et al., 2015). Diurnal temperature cycles also cause little diurnal changes in the $\mathrm{pH}$ of the rivers. For example, at neutral $\mathrm{pH}$, the solubility of calcite and dissolved $\mathrm{CO}_{2}$ increments with diminishing temperatures, creating a higher $\mathrm{pH}$ at lower temperatures (Bäckström et al., 2002; Viswanathan et al., 2015).

Variations of water temperature in the river can occur naturally or as a result of anthropogenic activities, such as point source and non-point source pollutant discharge from industrial, commercial, and housing sectors; they are single-handedly responsible for raising water temperatures. It can ultimately affect fisheries and aquatic resources (Caissie, 2006). Atmospheric conditions also play an important role in heat exchange processes at the water surface, incorporating the phase changes. Deforestation has been distinguished as a critical parameter in influencing the river thermal system (Beschta, 1997; Brown \& Krygier, 1970; Caissie, 2006; Ling et al., 2017). Potential stream channel modification can likewise be in charge of changes in river water temperature (Morse, 1972; Sinokrot \& Gulliver, 2000). In recent times, climate change has been a concern for the environmentalist in the global arena. With the rise in the temperature globally, the water temperature is also warming worldwide (Richards et al., 2018; Schindler, 2001; Sinokrot et al., 1995). Some degree of global warming seems to be inevitable due to the climate change in the environment. Distributions of aquatic organisms and fishes have been affected because the temperature in some rivers, owing to climate change, has reached lethal limits for fishes and aquatic organisms (Eaton et al., 1995a, 1995b).

Conceptually, water temperature is a proportion of the convergence of heat energy in a stream. All water contains heat energy; warmer water has a higher concentration of heat energy in comparison to cold water (Poole \& Berman, 2001). The stream temperature is generally in accordance with the groundwater temperature at the source (e.g., in headwater streams), and it increases proportionally to distance/stream order. The increment in water temperature does not follow a straightforward relationship, and the rate of increment is more noteworthy for small streams than big rivers (Caissie, 2006). The morphology of rivers can also influence thermal patterns; braided streams can encounter high water temperature because of their shallow channels exposed to meteorological conditions (Caissie, 2006; Mosley, 1983). In general, the thermal patterns of rivers are greatly affected by local climate, river conditions (physical, chemical, and biological), and geographical settings (Caissie, 2006). As there is an increasing consciousness about the effect of global warming in the aquatic ecosystem, so the study about the temporal and spatial pattern of river temperature becomes significant for the fluvial scientist and ecologists working on the river ecosystem (Carpenter et al., 1992; Clark et al., 2001; Flebbe et al., 2006; Hogg \& Williams, 1996; Mohseni et al., 2003; Wawrzyniak et al., 2012).

Early investigations of river water temperatures primarily concentrated on habitat use by aquatic plants and animals (Gibson, 1966).

Conventional methods for measuring the river water temperature are very costly, time-consuming, and moreover, provide information only regarding measurement at a specific point. Using these methods, it is also difficult to study the surface water temperature variation due to its spatial and temporal heterogeneity. At this juncture, remote sensing is a very useful substitute, as images from the satellites have a large spatial extent. Their periodic movement over the same area can be useful in temporal studies. Sensors of the satellite can catch the radiation energy of the different earth features in the visible region as well as the non-visible region of the electromagnetic (EM) spectrum. It can provide additional information, which otherwise is difficult to measure (Dash et al., 2002; Lamaro et al., 2013; Novo et al., 2006). This remote sensing 
technology is a stepping stone in the field of science, and it has several important applications like it can be used as a monitoring tool for resource development, classification purposes, and change detection analysis in land use patterns (Osgouei \& Kaya, 2017; Aslami \& Ghorbani, 2018; Behra et al. 2018; Fatemi \& Narangifard, 2019; Mi et al., 2019). Detection of the potential groundwater zones and water quality parameters for the inland system can also be successfully done using high-resolution sensor systems (Lamaro et al., 2013; Kumar et al., 2016; Altafi dadgar et al., 2017).

During the period of the late twentieth century, quick, innovative technological advances give us the accessibility of thermal infrared (TIR) images. Several researchers had used TIR satellite images to map the surface water temperature (Ahn et al., 2006; Alcântara et al., 2010; Torgersen et al., 2001). Compared with in-situ estimations, the thermal infrared remote detecting strategy gave an alluring option for estimating water temperatures and observing spatial patterns of thermal maps at different spatial scales (Ling et al., 2017). Interactions of all the energy between air and water body happen through a thin skin layer of the surface. This layer can also be detected with the help of remote sensing technology. In this layer, the water temperature is normally distinct from the temperature of the rest of the water mass. So there is a difference in the temperature, and this difference is very random in nature, and this randomness is driven by evaporative cooling, speed of the wind, and diurnal energy transition (Lamaro et al., 2013). Some authors exhibited that remotely estimated skin temperatures illustrate mass water temperatures (Lamaro et al., 2013; Schneider \& Mauser, 1996). Satellites equipped with thermal sensors can only observe water temperatures in higher order rivers due to their poor spatial resolution; however, they can also be incorporated in small stream studies using suitable transformations (Ling et al., 2017; Wawrzyniak et al., 2012).

Good spatial resolution, along with unremitting periodic coverage (16-day repeativity) and free availability of data, makes the Landsat system a reasonable alternative for studying surface water properties. The Landsat satellite arrangement permits the assemblage of many images to address seasonal and inter-year changeability (Lamaro et al., 2013; Wawrzyniak et al., 2012). The Landsat 8 Operational Land Imager (OLI) and Thermal Infrared Sensor (TIRS)is the $8^{\text {th }}$ satellite in the Landsat program. This satellite system has two thermal bands: band 10 and band 11 , and their central wavelength is at 10.9 and $12 \mu \mathrm{m}$ (approximately), respectively. These bands also have $100 \mathrm{~m}$ as their spatial resolution. The spatial resolution of Landsat- 8 is poorer when we compare it with Landsat-7, also known as Enhanced Thematic Mapper Plus (ETM +) because thermal bands of Landsat- 8 have a resolution of
$100 \mathrm{~m}$ in comparison to the Landsat- 7 thermal band, which has a spatial resolution of $60 \mathrm{~m}$. However, the dual TIR bands of Landsat 8 are highly efficient in thermal image assessment capability in contrast to the past single-channel satellites. For the Landsat-7 images acquired after 2003, there is a problem of data gap occurring in the downloaded images due to the failure of scan line corrector (Reuter et al., 2015; Wawrzyniak et al., 2012).

The impact of the stray radiance in Landsat 8 is prominent for the longer wavelength band, i.e., TIRS band $11(12.0 \mu \mathrm{m})$, than that in the shorter wavelength band, i.e., TIRS band $10(10.9 \mu \mathrm{m})$. Hence steadiness of band 10 is better in comparison to band 11 . Noise and stability performance for these two thermal bands are excellent, but since band 10 normally has adequate reliability performance in temperature evaluation, it should be utilized more than band 11(Montanaro et al., 2014).

Through a Landsat program, fluvial research has attained a new dimension. However, water temperature analysis was not given due attention (Baban, 1993; Frazier \& Page, 2000; Kay et al., 2005; Mertes et al., 1993; Wawrzyniak et al., 2012). The objective of the present study is to investigate temporal and spatial thermal patterns of the Ganga River at Varanasi and nearby places with the help of Landsat- 8 satellite images. In addition to this, the accuracy evaluation of the temperature values generated from the satellite images has also been performed by recording in-situ temperature values using the portable thermal sensor.

\section{Materials and Methods}

\section{Study Area}

Varanasi and its abutting regions have been chosen as the study area for this work. Varanasi is an eminent city in eastern Uttar Pradesh, India. The neighboring areas of Varanasi, including the city itself, is situated between $25^{\circ} 14^{\prime}$ to $25^{\circ} 23.5^{\prime} \mathrm{N}$ latitude and $82^{\circ} 56^{\prime}$ to $83^{\circ} 03^{\prime} \mathrm{E}$ longitude (Agnihotri et al., 2018; Das et al., 2020). The principal drainage system of the area is that of the Ganga River, which flows along the southern boundary of the region. The main tributaries of the Ganga in the area are the Varuna and the Assi rivers. In its journey of $2525 \mathrm{~km}$ from source to the sea, the River Ganga passes through the three most populated states, viz. Uttar Pradesh, Bihar, and West Bengal. The plain of the Ganga river is a flat alluvial plain having depression that is shallow and uneven in nature, and it also has a small eastward gradient. The Ganga River drainage basin is approximately $1.08 \times 10^{6} \mathrm{~km}^{2}$ (Bharati et al., 2011; Jain \& Singh, 2020; Mishra et al., 2014; Pandey \& Singh, 2017). Geomorphologically, the city of 
Varanasi and its nearby area come under the central Ganga plain. The average height of this city and its surrounding area from the mean sea level is approximately $76.19 \mathrm{~m}$. This whole region has a mostly smooth topography with moderate terrain variation and undulations (Kumar et al., 2012; Rai et al., 2010; Singh, 1996).

Varanasi region climate is primarily tropical in nature, and this place has a noticeable monsoon effect. The region experiences a very dry and extremely hot summer, mainly during April to June month and then the monsoon season starts from the month of July and goes up to September. The monsoon season here in this region is primarily warm and wet. After that winter season sets in, and its duration is mainly between the month of November to February, here one can experience cool and dry winter along with the heavy fog around December and January. The month of March and October is the spring and autumn season, respectively (Das et al., 2020). The region receives 40, 36, and $768 \mathrm{~mm}$ rainfall on average during winter, summer, and rainy seasons. The average temperature for these seasons ranged from $7.4-31.4,18.7-43$, to $21-36.9^{\circ} \mathrm{C}$, respectively. In the summer season, the temperature sometimes exceeds beyond $46{ }^{\circ} \mathrm{C}$. More than $90 \%$ of the average annual rainfall $(1050 \mathrm{~mm})$ occurs in the rainy season. In this region, the wind blows primarily in the west to the southwest from October to April and the east to the northwest in the remaining months (Kumar et al., 2012; Pandey \& Singh, 2017).

Varanasi is a city located on the banks of the Ganga River, and the river flowing through this region is very polluted; and the significant sources of pollution are effluents discharging from the industries, sewage generated from domestic wastes, and throwing away the dead human bodies into the river. Approximately there are around 1500 industries located nearby the Varanasi region, such as the textile and leather industry, chemical industry, and metal processing industries (Mishra \& Tripathi, 2008; Rai \& Tripathi, 2008; Rai et al., 2010).

As shown in Fig. 1, three confluence points were chosen to analyze the water temperature variation due to the discharge of effluents into the River Ganga. Its description is given in Table 1. Along with these confluence points, some mid-Ganga points were also selected for estimating midriver temperatures. Mid Ganga point, which is nearest to the reference point, is depicted as M1. All the other points have been marked in a similar order (for example, midGanga point situated near Industrial outlet is M2 and so on). The characteristics of the three confluence points are given in Table1.

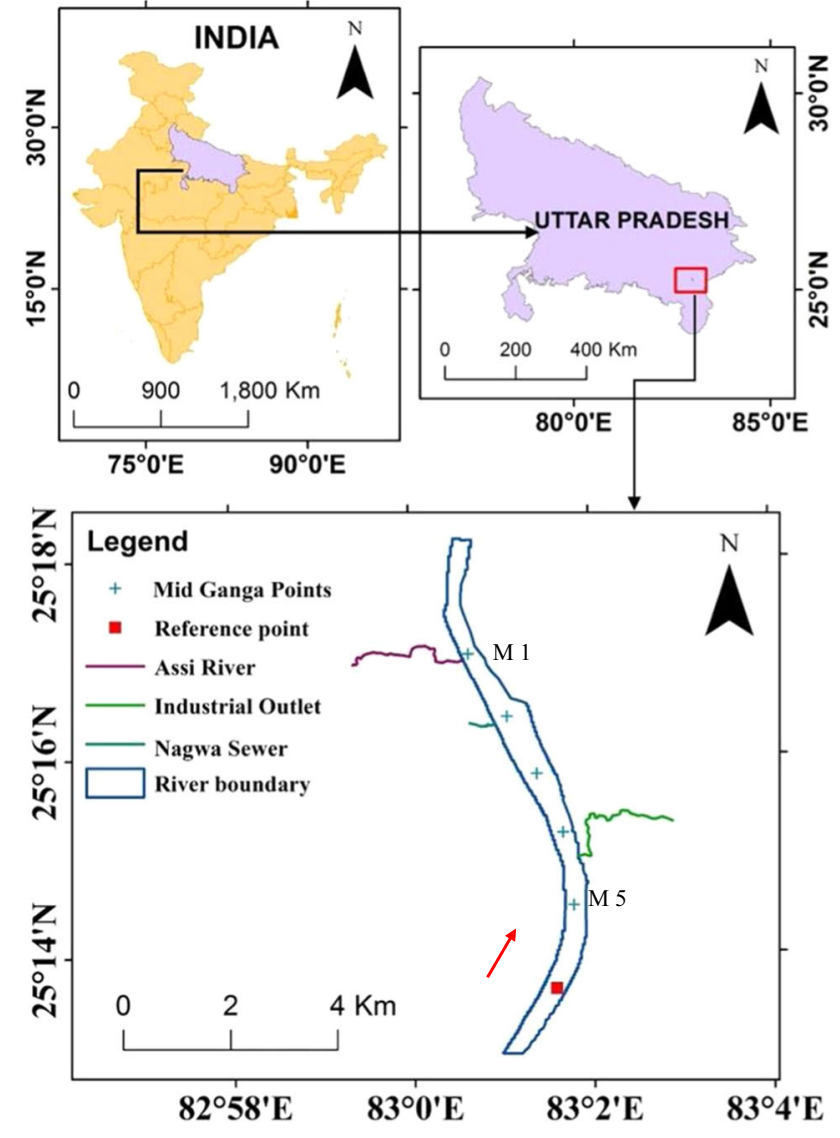

Fig.1 Location map of the study area. The head of the arrow shows the downstream direction

\section{Landsat Imagery Description}

The pertinent source for this work was a series of Landsat8 satellite images.Landsat- 8 satellite consists of eleven bands of different wavelengths, among which there are two thermal infrared (TIR) bands, namely, band 10 $(10.60-11.9 \mu \mathrm{m})$ and band $11(11.50-12.51 \mu \mathrm{m})$. The spatial resolution of TIR bands is $100 \mathrm{~m} \times 100 \mathrm{~m}$, and the rest of the bands has a spatial resolution of $30 \mathrm{~m}$, excluding pan (band 8), which has a $15 \mathrm{~m}$ resolution (Das et al., 2021; Reuter et al., 2015). The Landsat scenes selected for the study area were of path 142/row43. The chosen Landsat scenes were, between the years 2013 to 2018, having almost $0 \%$ cloud cover and were freely downloaded from the United States Geological Survey Earth Explorer site. Since the processed images of Landsat- 8 were first made available in March 2013, there is no Landsat- 8 data available prior to this month. All the images were Level $1 \mathrm{~T}$ products, which have been precision and terrain corrected in GeoTIFF format and are in the UTM Zone $44 \mathrm{~N}$ projection and WGS-84 as an ellipsoidal datum (http:// earthexplorer.usgs.gov) (Ling et al., 2017; Reuter et al., 2015). 
Table 1 Characteristic of the confluence points

\begin{tabular}{lll}
\hline S.No & Name of the Confluence point & Nature of Discharge \\
\hline 1 & Assi river outlet(C1) & Domestic and commercial sewage discharge in a huge amount \\
2 & Nagwa sewer outlet (C2) & Domestic sewage discharge \\
3 & Industrial outlet near DGPS station $(\mathrm{C} 3)$ & Domestic as well as industrial discharge \\
\hline
\end{tabular}

There are several criteria's for selecting the images described by Lamro et al., (2013) such as:-

(1) Images from different seasons should be downloaded in order to have a better analysis for water surface temperature calculation.

(2) Images should consist of zero percent cloud cover, if possible.

By keeping these criteria's in mind, cloud-free images for the month of February, June, and November for each year between 2013 and 2020 has been downloaded, and monsoon period(July-September) images have been avoided due to the high percentage of cloud cover.

\section{Methodology}

In this work, we are monitoring the thermal patterns in the River Ganga at the Varanasi stretch. The analysis was done by using Landsat 8 time-series images from 2013 to 2020, and the steps are shown in Fig. 2.

\section{Atmospheric Correction}

The thermal bands of the satellites are affected by atmospheric effects. These effects will induce noise in the radiance signal and which in turn can cause the computational error. So to remove these noises, we have to do atmospheric correction so that it can minimize atmospheric effects. For the corrected water surface radiance, several atmospheric parameters like $\mathrm{L}_{\lambda \text { up }}$ (upwelling radiance), $\tau$ (atmospheric transmissivity), $L_{\lambda \mathrm{d}}$ (downwelling radiance) will be required. In addition to these parameters, ' $\varepsilon$ ' (water emissivity) value will also be needed. Atmospheric parameters $\left(\mathrm{L}_{\lambda u p}, \tau, L_{\lambda d}\right)$ were obtained from 'Atmosphere Correction Parameter Calculator'(http://www.atmcorr.gsfc. nasa.gov/) (Lamaro et al., 2013; Ling et al., 2017). In this work, the emissivity of water was taken as 0.9885 (Ling et al., 2017; Simon et al., 2014).

\section{Making of the Water Masks}

At first, a water mask has to be generated for delineating water bodies in the image. For generating the water mask, we have to calculate Normalized Difference Water Index (NDWI) for each of the images under consideration. NDWI is a band rationing technique where band 3 (green) and band 5(Near Infrared; NIR) of the Landsat- 8 images are required to estimate the NDWI value. Band 3 has a wavelength range between 533 and $590 \mathrm{~nm}(\mathrm{~nm})$, and band 5 wavelength varies between 851 and $879 \mathrm{~nm}$ (Gautam et al., 2015; Sarp \& Ozcelik, 2017). NDWI is calculated according to the following formula:

$\mathrm{NDWI}=\frac{(\text { GREEN }- \text { NIR })}{(\text { GREEN }+ \text { NIR })}$

After calculating the NDWI value, pixels containing water bodies will be highlighted. If NDWI $>0$, it features water, and it is non-water if NDWI $\leq 0$. Positive values suggest water features, whereas zero or negative values indicate soil and terrestrial vegetation (Nandi et al., 2017). In this work, the threshold has been selected as 0.15 (Ghosh et al., 2020). This processed image was then used to delineate the river boundary for the study area, and its shapefile was created. This shapefile was further used to subset the thermal images in Arc GIS.

\section{Surface Water Temperature Calculation}

For the estimation of the surface temperature of river water, Top of Atmosphere (TOA) spectral radiance needs to be calculated first, using the formula:

$L_{\lambda}=M_{L} * Q_{\text {cal }}+A_{L}$

where $L_{\lambda}$ is the TOA spectral radiance (Watts $/\left(\mathrm{m}^{2-}\right.$ $\left.\left.{ }^{*} \operatorname{srad} * \mu \mathrm{m}\right)\right) . M_{L}$ is Band-Specific Multiplicative re-scaling factor from metadata. $Q_{\text {cal }}$ is quantized, and calibrated standard product pixel value $\mathrm{DN}$ and $A_{L}$ is Band-Specific additive re-scaling factor from metadata. Afterward, the calculated TOA value is corrected by using the formula:

$L_{\lambda \text { cor }}=\tau \cdot \varepsilon \cdot L_{\lambda}+L_{\lambda u p}+L_{\lambda d}(1-\varepsilon) \cdot \tau$

where symbols have the usual meanings, and these meanings have already been described in the atmospheric correction section. Then, with the use of formula number 4 , we can convert the spectral radiance into brightness temperature in degree Celcius: 
Fig. 2 Flowchart for monitoring the thermal pattern of the river using Landsat- 8 images

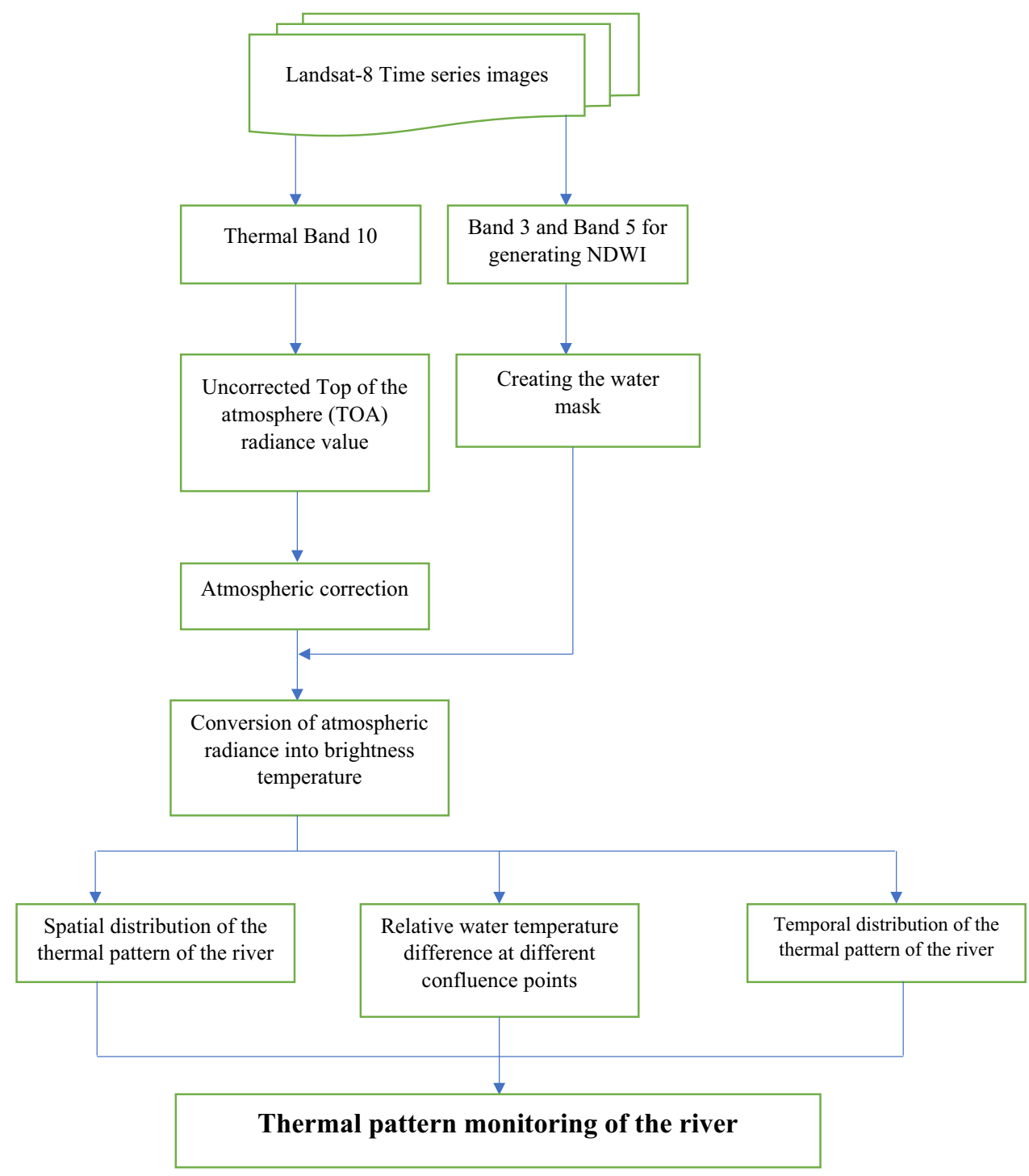

$T=\left[K 2 /\left(\ln \left(\left(K 1 / L_{\lambda \text { cor }}\right)+1\right)\right)\right]-273.15$

where $\mathrm{K} 1$ and $\mathrm{K} 2$ are the thermal constants of the satellite (Barsi et al., 2014; Rajeshwari \& Mani, 2014). $\mathrm{M}_{\mathrm{L}}$ and $\mathrm{A}_{\mathrm{L}}$ values for the required area of interest are 0.000342 and 0.1 , respectively. $\mathrm{K} 1$ and $\mathrm{K} 2$ values of Landsat- 8 satellite's TIR band-10 for the area of interest are 774.8853 and 1321.0789, respectively. Values of all these parameters can be found in satellite imagery's metadata file, which is downloaded along with the satellite imagery (Rajeshwari \& Mani, 2014).

\section{Portable Thermal Sensor}

The sensing gadget consists of hardware and software parts. The hardware portion includes the temperature sensor "TSY01," which is connected to an Arduino microcontroller, and Bluetooth is also attached to this system for data transfer. This whole system has been supplied power for its functionality with the help of a power bank, which is portable in nature (Daigavane \& Gaikwad, 2017; Das et al., 2019). This portable thermal sensor can be commanded with the help of a mobile app, and the temperature which is recorded with this sensor can be kept in the app itself as a text file. The text file which is generated by the app can be transported to the ArcGIS environment for visualization. Pre-calibration of this gadget has been done by MEAS company and has an accuracy of $\pm 0.1{ }^{\circ} \mathrm{C}$. The Block diagram for this sensor system is shown in Fig. 3, and the complete sensor system setup is depicted in Fig. 3a. This portable setup for measuring the in-situ temperature of the river has several advantages over temperatures recorded at hydrological stations. With the help of a portable thermal sensor, one can measure the in-situ temperature approximately at the same time when there is a satellite overpass, but the hydrological stations are limited to measuring 
Fig. 3 a Block diagram of the sensor system setup and b Portable thermal sensor
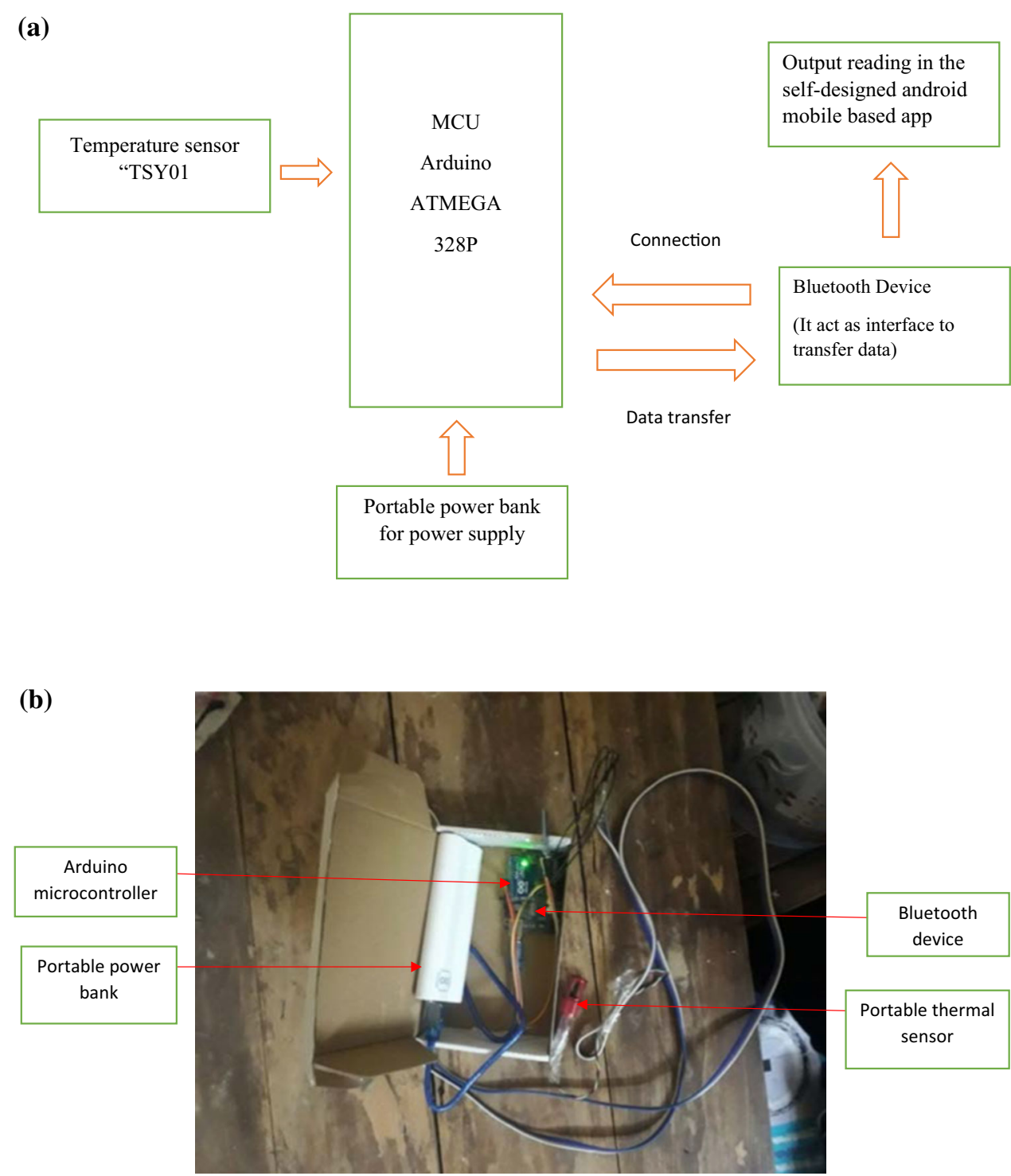

temperatures at fixed timings. So, there will be more variation between the in-situ temperatures recorded at the hydrological station than temperatures estimated from the satellite; as this variation increases, the uncertainty in results will be enhanced. Another advantage of having the portable setup is that one can take several points in the study area chosen for in-situ measurement; this reduces the uncertainty and RMSE (Root Mean Square Error) value between the estimated and observed temperatures.

\section{Results}

\section{Validation of Estimated Water Temperature}

For the validation of the temperature calculated from satellite images, the results were compared with the values of water temperature observed through the portable sensor system. For this purpose, six images were selected whose acquisition dates are 25 December 2018, 10 January 2019, 11 February 2019, 4 March 2021, 20 March 2021, 5 April 2021, respectively, and scene IDs are "LC08_L1TP_142043_ 20181225_20190129_01_T1”, “LC08_L1TP_142043_ 20190110_20190131_01_T1”, “LC08_LITP_142043 _20190211_20190222_01_T1”, “LC08_L1TP_142043_ 20210304_20210312_02_T1", “LC08_L1TP_142043 _20210320_20210328_02_T1”, “LC08_L1TP_142043_ 20210405_20210409_02_T1," respectively. Since the satellite overpass through the study area was known beforehand from the Landsat overpass calendar issued by USGS along with the approximate overpass time, the in-situ data were recorded for several points in the study area. Around 120 sample points were chosen 
along both the banks and mid-section of River Ganga, for which in-situ temperature was measured, and a good correlation along with RMSE value of 0.956 was observed as shown in Fig. 4a. To mark the coordinates of the points, "Garmin Etrex 30" GPS system was used. The GPS device saves the point (LAT and LONG) in degrees, minutes and seconds format, e.g., $34^{\circ} 26^{\prime} 31.73^{\prime \prime} \mathrm{N}$ and $74^{\circ} 09^{\prime} 14.38^{\prime \prime} \mathrm{E}$. But this format needs to be converted into degree decimal, e.g., $34.442 \mathrm{~N}$ and 74.153E. Now we have to use the ArcGIS software for plotting these points on the layer which has already been created in this software, and this layer is comprising temperature of the water surface, and then with the help of the "extract value to points" tool of the above-mentioned software, we can get the temperature values of these plotted points. These points will now show some temperature values as an attribute, which can be seen in the software itself, and those values are satellite-determined temperature. These temperature values are computed with the steps written in the 'surface water temperature calculation' section. For each satellite overpass day, 20 in-situ temperature points have been recorded for the satellite-derived temperature validation. In the map, 20 in-situ points location has been shown. For all six sampling days, the in-situ temperature has been measured at these places.

\section{Spatio-Temporal Variation of River Thermal Profile}

\section{Spatial Variation of River Water Temperature}

The temperature map prepared from the satellite image, as shown in Fig. 5, depicts the spatial variation of river surface temperature over the study area. The river stretch in the figure is around10 kilometers long; its width varies from 230 to $700 \mathrm{~m}$ over the stretch and is flowing toward the north direction. As it is such a wide river, the effect of effluent discharge is not visible on the thermal map with a coarse resolution.

But a gradual pattern of thermal variation over a range of temperature can be observed from the images, with the variations generally remaining low for Feb and Nov months and high during June. It was also observed that water temperatures along the bank were relatively higher than in the mid-section. To get a better idea of spatial variation of temperature over the stretch, a tabular form of representation is also given in Table 2. Some of the years and months have been presented in Table 2. Temperature values are in degree Celsius $\left({ }^{\circ} \mathrm{C}\right) .{ }^{\prime} \mathrm{C}$ ' depicts the confluence points, and ' $\mathrm{M}$ ' depicts the mid-Ganga points shown as star mark in Fig. 1.

It is clearly evident from Table 2 that temperature at all three confluence points remains higher throughout the study period than mid-Ganga region. This indicates that effluent discharge into a large river has little influence on the overall river temperature, and its effect can only be observed along the banks, some meters downstream of the

(b)

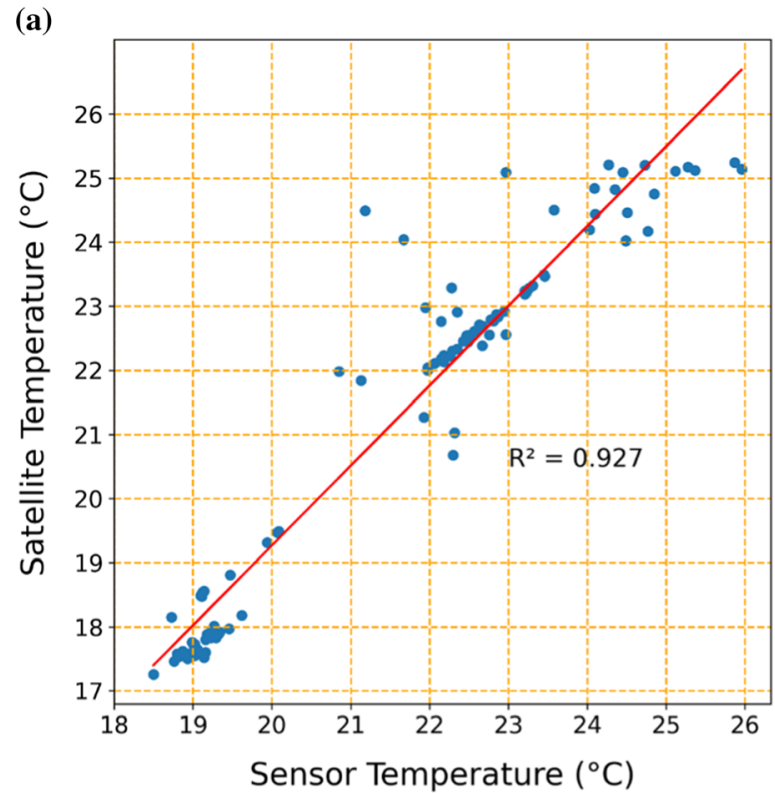

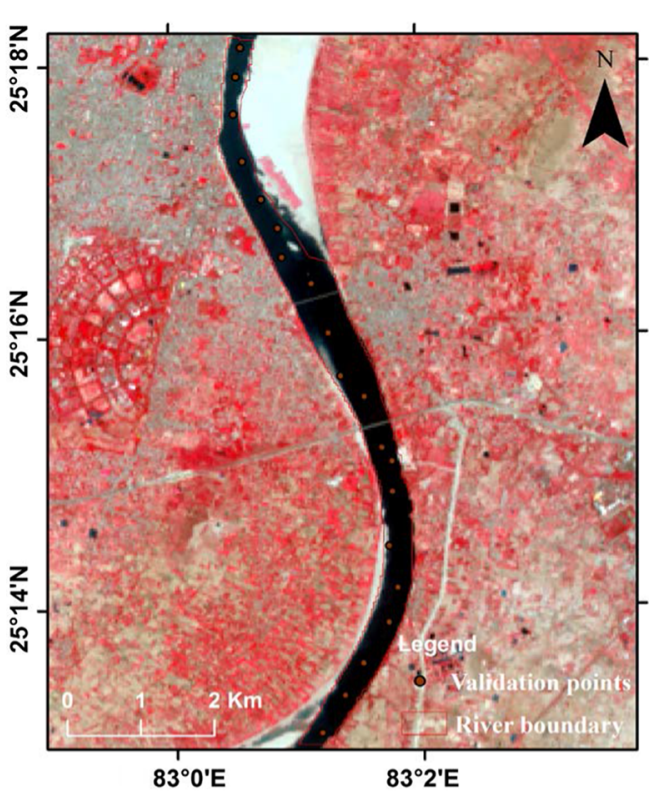

Fig. 4 a Correlation graph between the temperature observed from the portable thermal sensor and satellite-derived temperature. $\mathbf{b}$ Map of the insitu temperature measurement point 
Fig. 5 Spatial distribution of river thermal profile
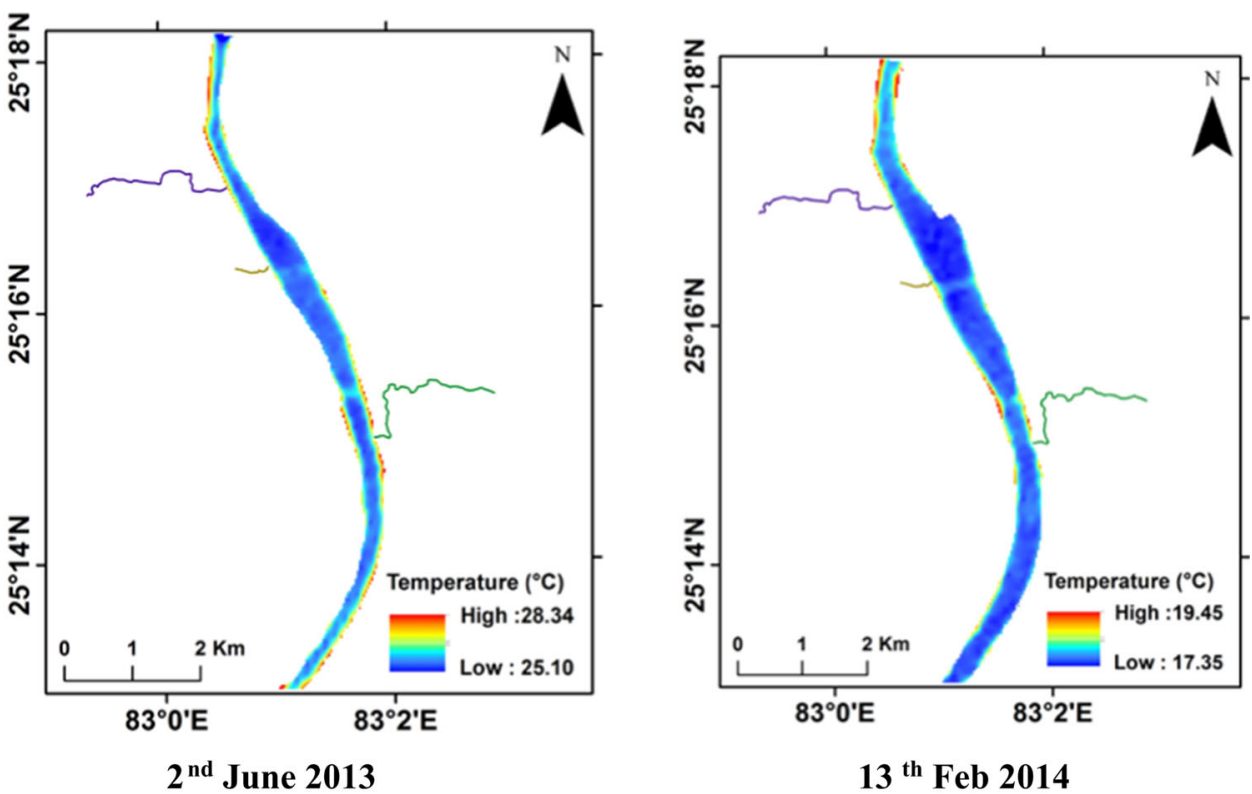

$13^{\text {th }}$ Feb 2014

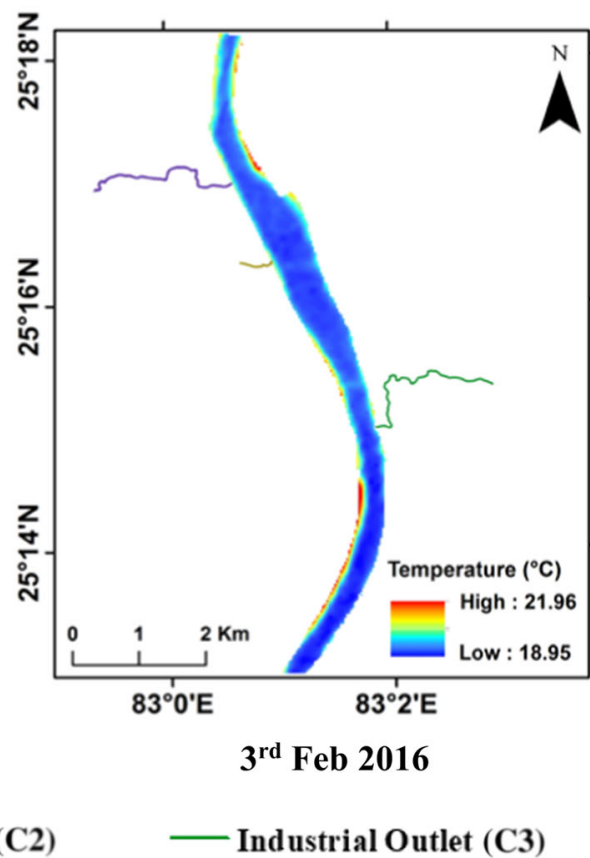

confluence. The variation between confluences and the mid-Ganga region increases during the month of June and remains relatively less during February and November.

\section{The Relative Water Temperature Difference in Comparison to the Reference Point}

Reference point has been chosen for calculating the relative water temperature variation in the river (Ling et al., 2017). The point is chosen on the river, where it is in pristine condition. So, in this case, the reference point has been selected on the river before it enters Varanasi city, and it has been assumed that the river water at this point is fresh and clean. The reference point temperature is assigned as zero value in all the cases, and the temperature values are in ${ }^{\circ} \mathrm{C}$.

From Tables 3, 4, 5, 6, 7, 8, 9, 10; it is clear that temperatures at the confluences are relatively higher for all the years. All the confluence points were within a range of seven kilometers downstream from the reference point. Among all the confluence points considered for the study, the 'Confluence Point 3' had the least relative temperature 
Fig. 5 continued

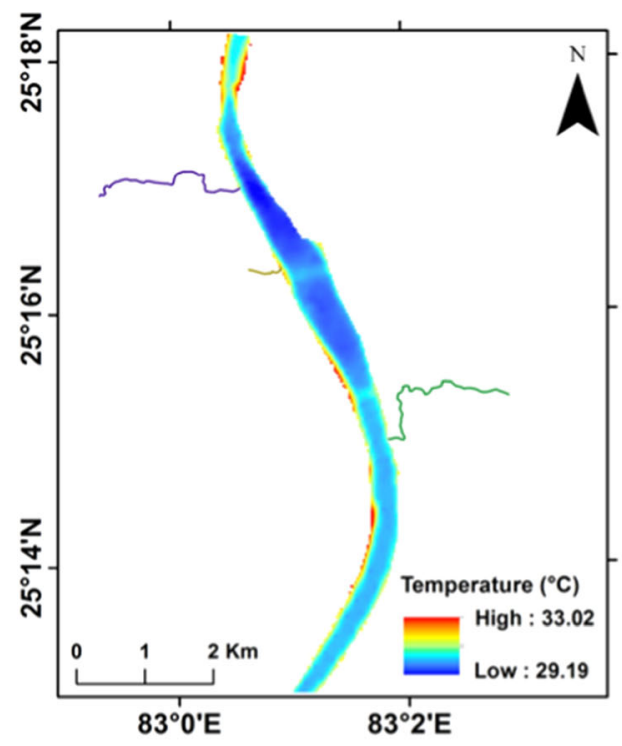

$13^{\text {th }}$ June 2017

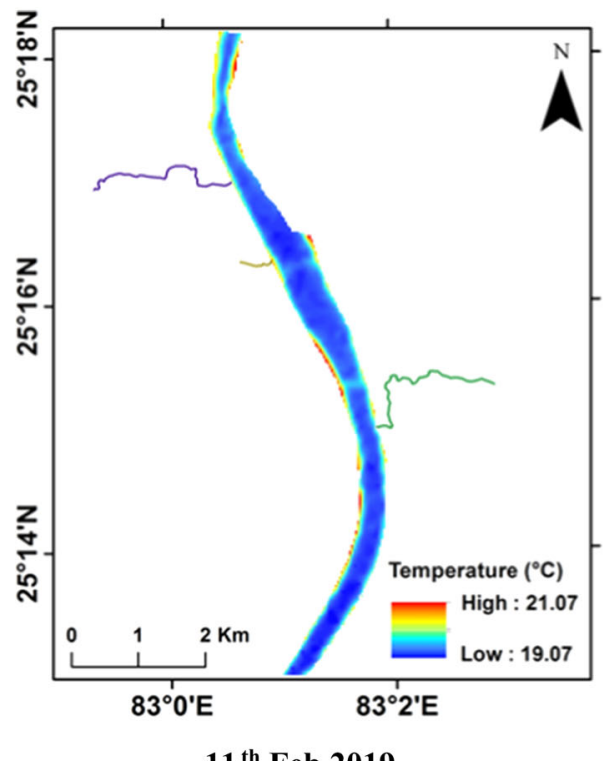

$11^{\text {th }}$ Feb 2019
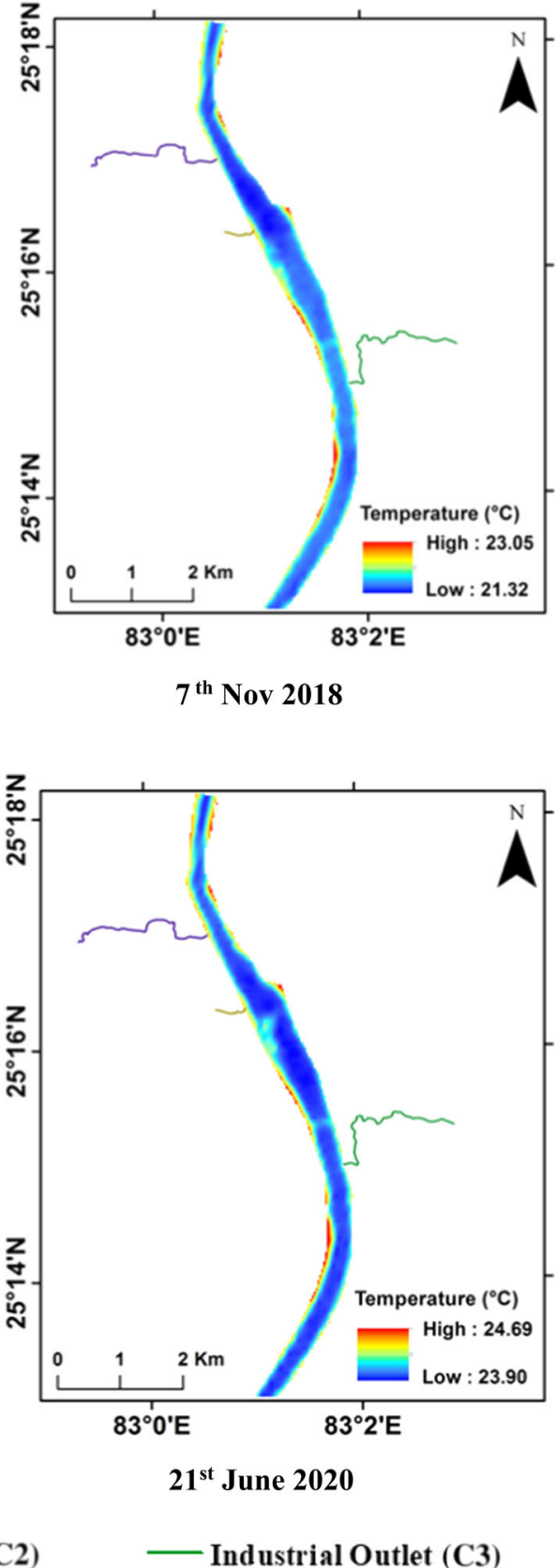

variation for the selected years. It may be because the source of pollution (i.e., iron industry) is located at a distance from the point of confluence. The industry treats its waste before discharging it into the sewer. 'Confluence Point 2' shows the maximum temperature fluctuation of $2.71{ }^{\circ} \mathrm{C}$ for February 2016. This has been the maximum relative temperature variation. In February, for all of the considered time periods, the relative temperature shows maximum variation. During the months of June, the reference point has a higher temperature value as compared to the mid-Ganga points (M1-M5). This may be because the region where the reference point has been placed, the river, is narrow in that region. In addition to that presence of the sandbar in that region further elevates the water temperature, particularly in the summer region. This may be one of the probable reasons for low relative temperature variation in June as compared to February. In June 2020, there has been a minimal variation of relative surface water temperature for three confluence points. During this period, the country was in the grip of the lockdown phase imposed by the government due to the COVID-19 pandemic. Due to the lockdown, most industries have been closed, so the 
Table 2 Spatial variation of river temperature

\begin{tabular}{llllllllllll}
\hline Year and Month & C 1 & C 2 & C 3 & M 1 & M 2 & M 3 & M 4 & M 5 & $\begin{array}{l}\text { Min } \\
\text { Temp }\end{array}$ & $\begin{array}{l}\text { Max } \\
\text { Temp }\end{array}$ & $\begin{array}{l}\text { Ref. pt } \\
\text { Temp }\end{array}$ \\
\hline 2013 June & 28.30 & 28.21 & 27.78 & 25.12 & 25.28 & 25.19 & 25.31 & 25.23 & 25.10 & 28.34 & 26.45 \\
2014 Feb & 19.40 & 19.32 & 19.29 & 17.63 & 17.65 & 17.58 & 17.48 & 17.57 & 17.35 & 19.45 & 17.35 \\
2015 Nov & 24.98 & 24.95 & 24.38 & 23.97 & 23.98 & 23.13 & 23.19 & 23.12 & 23.07 & 25.14 & 23.08 \\
02,016 Feb & 21.63 & 21.68 & 21.58 & 19.01 & 19.15 & 19.12 & 19.10 & 19.11 & 18.95 & 21.96 & 18.97 \\
2017 June & 32.71 & 32.96 & 32.18 & 29.20 & 29.46 & 29.38 & 30.75 & 30.78 & 29.19 & 33.02 & 30.85 \\
2018 Nov & 22.97 & 23.02 & 22.43 & 21.34 & 21.70 & 21.63 & 21.54 & 21.72 & 21.32 & 23.05 & 21.34 \\
2019 Feb & 21.04 & 21.06 & 20.57 & 19.34 & 19.31 & 19.31 & 19.23 & 19.18 & 19.07 & 21.07 & 19.07 \\
2020 June & 24.68 & 24.57 & 24.09 & 23.98 & 23.95 & 23.94 & 23.93 & 23.91 & 23.90 & 24.69 & 23.90 \\
\hline
\end{tabular}

Table 3 Relative surface water temperature variation for the year 2013

\begin{tabular}{lll}
\hline & June & November \\
\hline Confluence Pt. 1 & 1.85 & 1.86 \\
Confluence Pt. 2 & 1.76 & 1.84 \\
Confluence Pt. 3 & 1.33 & 1.34 \\
\hline
\end{tabular}

Table 4 Relative surface water temperature variation for the year 2014

\begin{tabular}{llll}
\hline & February & June & November \\
\hline Confluence Pt. 1 & 2.05 & 1.84 & 1.77 \\
Confluence Pt. 2 & 1.97 & 1.81 & 1.73 \\
Confluence Pt. 3 & 1.94 & 1.35 & 1.38 \\
\hline
\end{tabular}

Table 5 Relative surface water temperature variation for the year 2015

\begin{tabular}{llll}
\hline & February & June & November \\
\hline Confluence Pt. 1 & 1.95 & 1.87 & 1.90 \\
Confluence Pt. 2 & 1.96 & 1.85 & 1.87 \\
Confluence Pt. 3 & 1.88 & 1.36 & 1.30 \\
\hline
\end{tabular}

industrial waste discharge was also very low in this period. So the river nearby the confluence point becomes significantly less polluted, and the temperature difference is minimal.
Table 6 Relative surface water temperature variation for the year 2016

\begin{tabular}{llll}
\hline & February & June & November \\
\hline Confluence Pt. 1 & 2.66 & 1.81 & 1.89 \\
Confluence Pt. 2 & 2.71 & 1.82 & 1.87 \\
Confluence Pt. 3 & 2.61 & 1.35 & 1.31 \\
\hline
\end{tabular}

Table 7 Relative surface water temperature variation for the year 2017

\begin{tabular}{llll}
\hline & February & June & November \\
\hline Confluence Pt. 1 & 2.03 & 1.86 & 1.91 \\
Confluence Pt. 2 & 1.99 & 2.11 & 1.88 \\
Confluence Pt. 3 & 1.87 & 1.33 & 1.32 \\
\hline
\end{tabular}

Table 8 Relative surface water temperature variation for the year 2018

\begin{tabular}{llll}
\hline & February & June & November \\
\hline Confluence Pt. 1 & 2.04 & 1.93 & 1.63 \\
Confluence Pt. 2 & 1.98 & 1.96 & 1.68 \\
Confluence Pt. 3 & 1.88 & 1.33 & 1.09 \\
\hline
\end{tabular}

\section{Temporal Variation of River Water Temperature}

The temporal variation of temperature over the years has been shown in Figs. 6, 7 and 8 for all three confluence points.

Over the years, all three confluences show a similar trend in temperature variation for the given months, with temperatures rising sharply from February to June and then 
Table 9 Relative surface water temperature variation for the year 2019

\begin{tabular}{llll}
\hline & February & June & November \\
\hline Confluence Pt. 1 & 1.97 & 1.89 & 1.64 \\
Confluence Pt. 2 & 1.99 & 1.92 & 1.67 \\
Confluence Pt. 3 & 1.50 & 1.37 & 1.35 \\
\hline
\end{tabular}

Table 10 Relative surface water temperature variation for the year 2020

\begin{tabular}{llll}
\hline & February & June & November \\
\hline Confluence Pt. 1 & 1.97 & 0.78 & 0.97 \\
Confluence Pt. 2 & 1.92 & 0.67 & 0.81 \\
Confluence Pt. 3 & 1.64 & 0.19 & 0.29 \\
\hline
\end{tabular}

gradually decreasing from June to November. The maximum temperature was observed in June 2014 for 'Confluence points 1 and 2' and in June 2017 for the $3^{\text {rd }}$ point. Temperature values for June 2016 for all three points were abnormally low compared to the rest of the years. For the 'Confluence points 1 and 2', February 2014 has the lowest February-season temperature, and February 2017 has the highest February-season temperature. The 'Confluence point 3' has the highest February-season temperature in February 2016. All three confluence points represent the highest November-season temperature during November 2015. There was no data available for February 2013 as the satellite images of Landsat- 8 were released by USGS only from March 2013.

\section{Discussion}

With the analysis of temporal and spatial variation of the thermal pattern of the river, in the considered stretch, with the help of the Landsat- 8 satellite, it can be seen that confluence points and their adjoining areas have higher temperature differences in comparison to mid-Ganga surface temperature. Point source pollutants may introduce lateral heterogeneities. Some only warm a $25-30 \mathrm{~m}$ wide area along the banks of the river, depending upon the amount of discharge, which is progressively diluted into the main river (Ling et al., 2017; Wawrzyniak et al., 2012). In this work, alterations in the temperature caused by metrological and hydrological conditions are not taken into account. In general, the magnitude of thermal variation caused by effluents discharge at the confluence points in summer is more than that in winter. However, the amount of thermal change was approximately the same for confluence points 1 and 2 in the same season, such as in November 2015 and February 2019, when the differences were only $0.03{ }^{\circ} \mathrm{C}$ and $0.02{ }^{\circ} \mathrm{C}$, respectively. From the temporal variation graph, we can also see that the June 2016 temperature was significantly lower for all the three confluence points than in other years. One reason for this difference may be attributed to different meteorological and hydrological conditions existing during that period. In June 2020, the river temperature showed a relatively lower value compared to other June seasons (except June 2016). This could be attributed to the fact that the country was

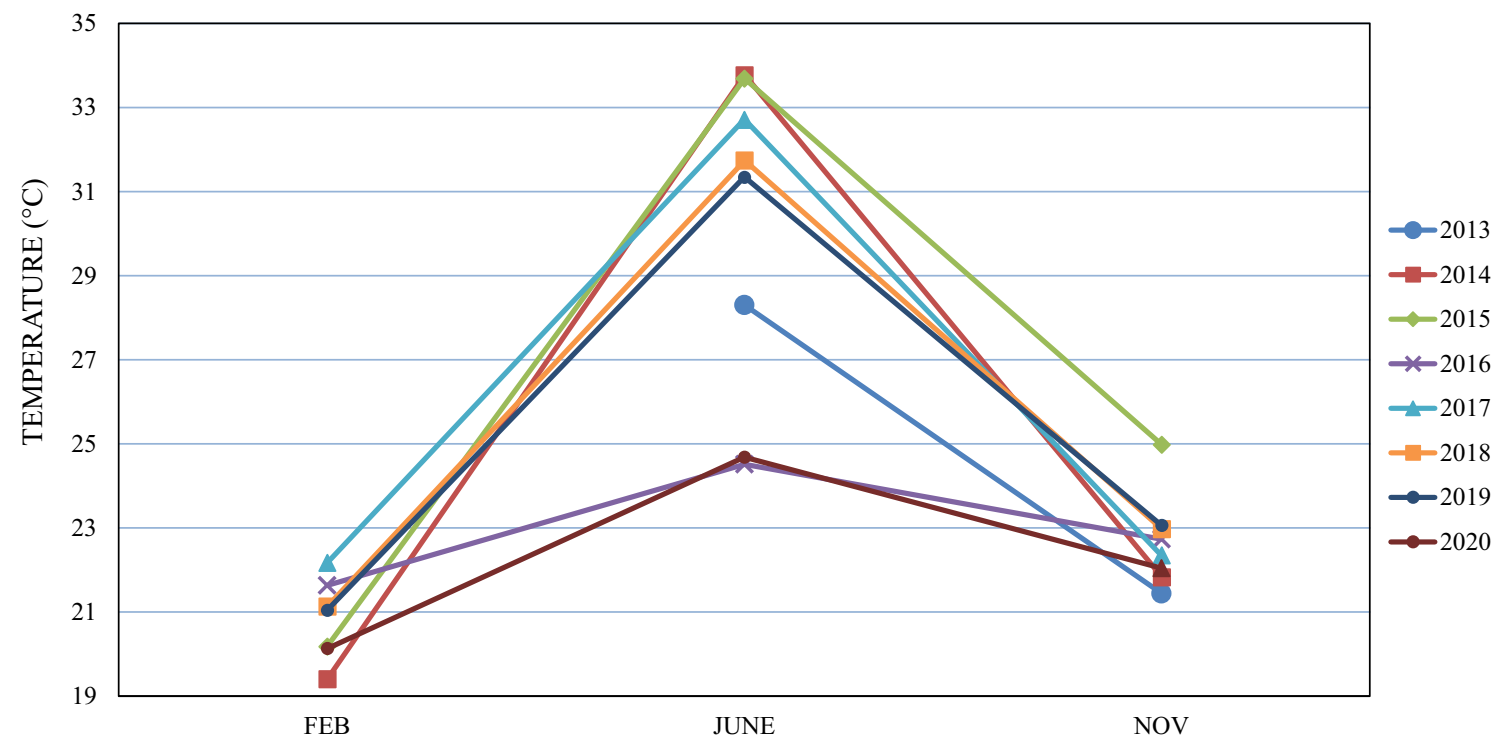

Fig. 6 Temporal temperature profile graph for Confluence Point 1 


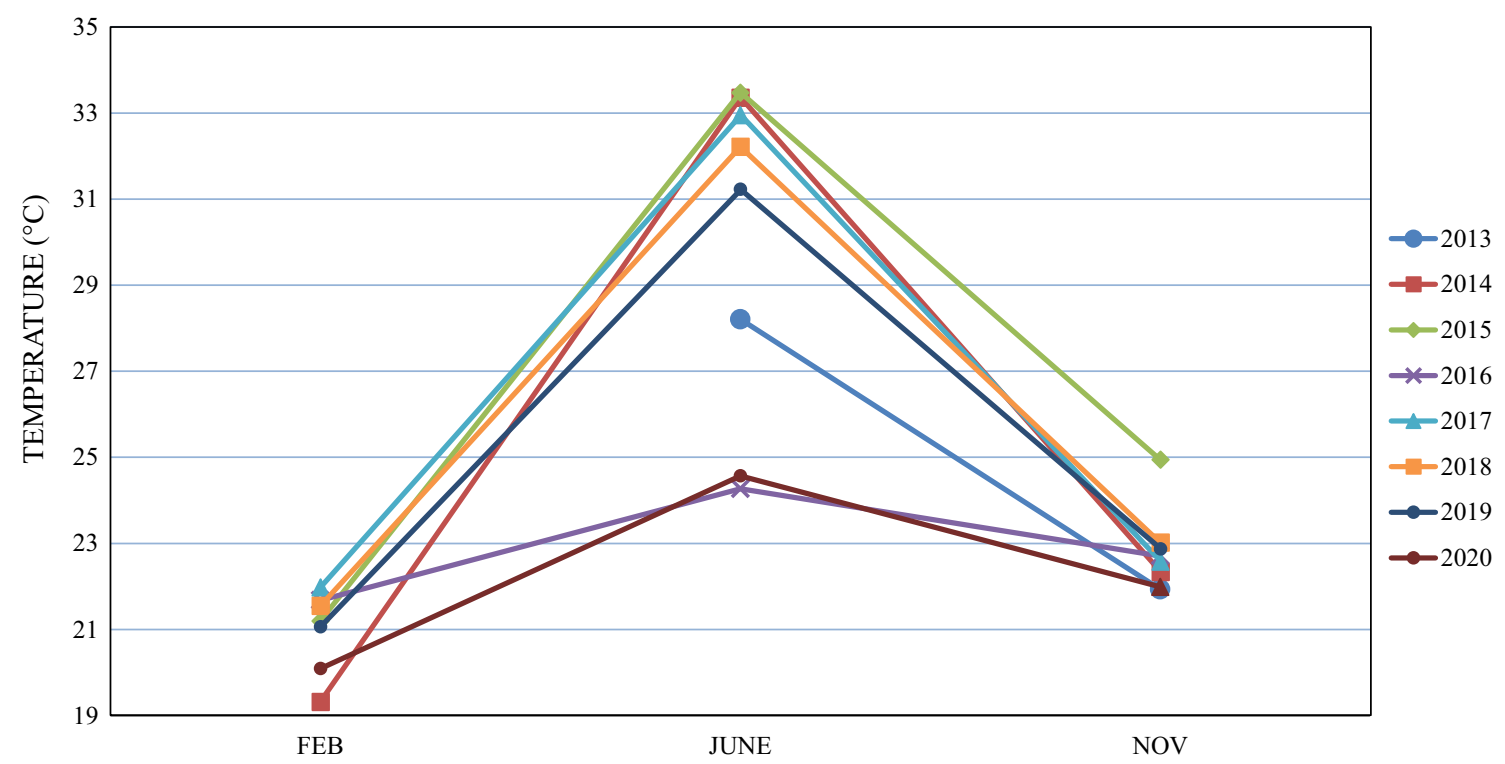

Fig. 7 Temporal temperature profile graph for Confluence Point 2

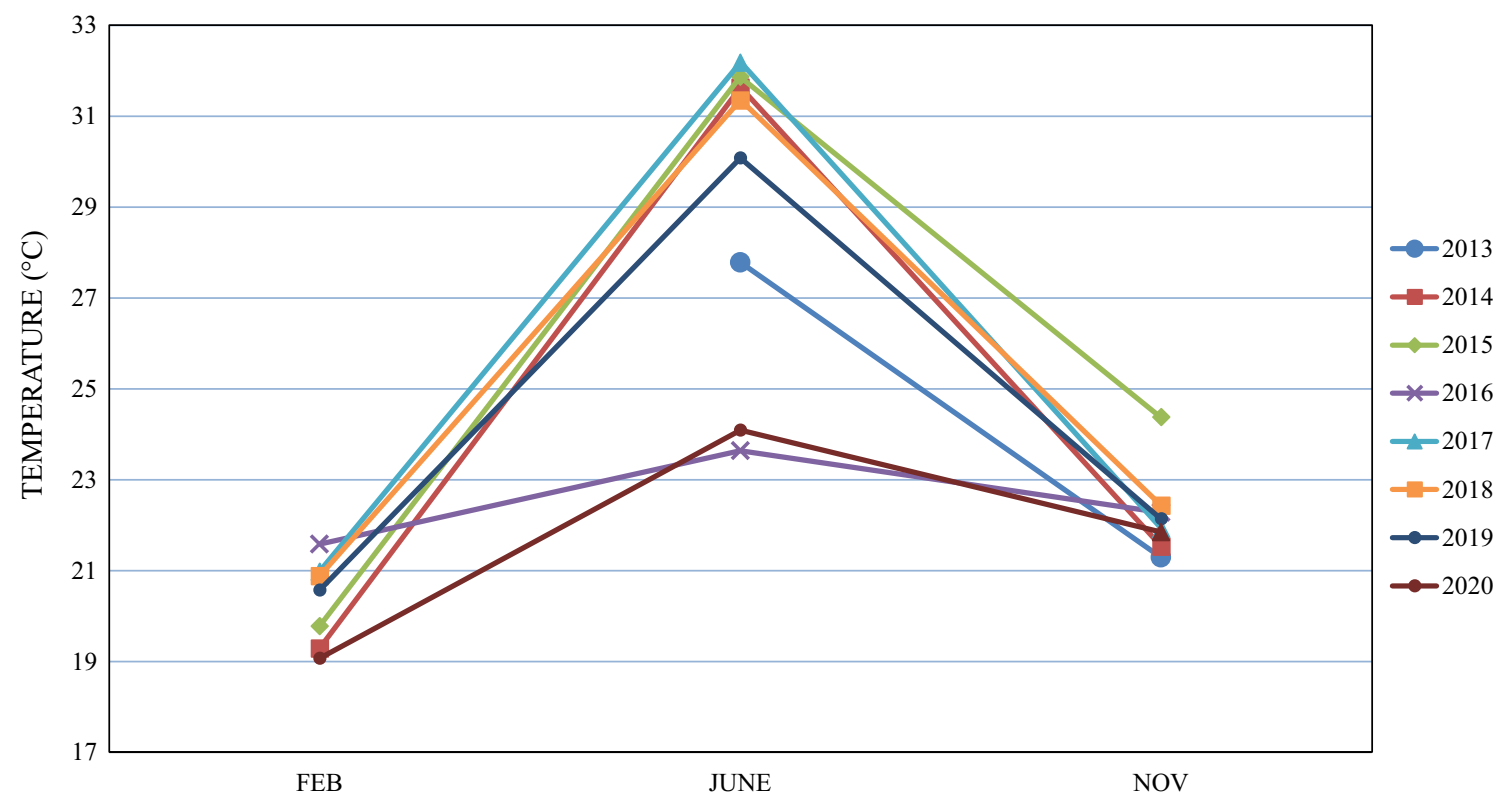

Fig. 8 Temporal temperature profile graph for the Confluence Point 3

under lockdown during that period (Garg et al., 2020). The industries were primarily closed, which reduced the carbon emission. The concentrations of $\mathrm{PM}_{10}$ and $\mathrm{PM}_{2.5}$ have witnessed the maximum reduction. Due to the carbon emission depletion, the air temperature gets decreases (Mahato et al., 2020). The air temperature directly relates to water temperature (Webb, 1996), so water temperature also depicts a lowering trend during that period. In this work, we also analyze the spatial extent of thermal patterns in the River Ganga. With all the freely available Landsat datasets, the general trend of thermal patterns in the river can be observed, but for the daily basis study and analysis, Landsat datasets are not enough. And the abrupt change in temperature of the river can be observed near the three confluence points. This spatial temperature variation for some seasons is shown in Table 2.

The efficiency of the given algorithm is primarily hampered by the uncertainties associated with temperature estimation from Landsat series satellite data. In practicality, several sources of ambiguity are associated with the temperature calculation of river surface (Handcock et al., 2006; Ling et al., 2017). Other factors that affect the 
temperature calculation accuracy are sensor calibration, instrument noise, and in-scene spectral variability from non-water materials (Kay et al., 2005; Lamaro et al., 2013). One conceivable technique to decrease the effects brought about by uncertainty is utilizing the Landsat time-series data, as an extensive number of observations can help make the outcome robust and dynamic. As mentioned earlier, TIR images have poor resolution. It can only measure water temperature for broad rivers; in this work, the river considered for analysis varies roughly around 230 to $700 \mathrm{~m}$ over the study stretch. With the help of image enhancement algorithms, the surface water temperature for narrow streams can also be computed very easily (Cherkeuer et al. 2005; Ling et al., 2017). The advanced water temperature estimation algorithms can also be applied to enhance the accuracy of the analysis of thermal patterns determined from Landsat- 5 thermal images $(120 \mathrm{~m}$ spatial resolution) or Landsat-7 thermal images $(60 \mathrm{~m}$ spatial resolution) (Galiano et al. 2012). In practice, if other additional data such as hydrological or meteorological information are accessible, they can be included in the analysis for more accuracy and improvement of the results. The amalgamation of the current study and results estimated from simulated water temperature models needs further exploration because these studies' results have mutual benefits (Cristea \& Burges, 2009).

It could be stated that, the process adopted for this analysis gives a helpful modus operandi to fill in the scanty in-situ observation of the surface temperature of the river. This algorithm may also be applicable on a global level due to the global coverage of Landsat satellites.

\section{Conclusion}

In the present study, we have developed a strategy to monitor the spatial and temporal variation in the thermal pattern of the River Ganga at Varanasi, using LANDSAT-8 satellite data. For this study, 29 satellite images were used, out of which 23 were used to prepare thermal maps, and six were used for validation purposes. The validation of satellite-measured temperatures was done by in-situ temperature measurements, for which we have built our own portable thermal sensor. The results illustrate that water surface temperature at the confluence points was relatively higher due to incoming effluents. At the same time, the mid-Ganga temperature was not affected by the discharge of the effluent. Although a good correlation was observed with in-situ data, other possibilities for further improvement could still be considered. The in-situ sampling has been done in such a manner so that it has covered almost the entire stretch by keeping logistics demand in consideration. Last but not least, as river temperature is a vital parameter for river ecology, hence the study of the thermal profiles of the rivers was carried out with utmost importance.

Acknowledgements Authors would like to take this occasion to expresses their thankfulness toward Dr. Prabhat Kumar Singh Dixit, HOD of Civil Engineering Department, IIT (BHU), for continuously inspiring to carry forward this study. The authors would like to thank USGS earth explorer for online availability of Landsat-8 data. Authors will also like to thank Mr. Vaibhav for his contribution in making the portable thermal sensor.

Funding Not applicable.

Availability of Data and Material Data have been retrieved from USGS database, which is an open source database.

\section{Declarations}

Conflict of interest Authors declare no conflict of interest.

\section{References}

Agnihotri, A. K., Ohri, A., \& Mishra, S. (2018). Impact of green spaces on the urban microclimate through Landsat 8 and TIRS Data, in Varanasi, India. International Journal of Environment and Sustainability, 7(2), 72-80.

Ahn, Y., Shanmugam, P., Lee, J., \& Kang, Y. (2006). Application of satellite infrared data for mapping of thermal plume contamination in coastal ecosystem of Korea. Marine Environmental Research. https://doi.org/10.1016/j.marenvres.2005.09.001

Alcântara, E. H., Stech, J. L., Lorenzzetti, J. A., Bonnet, M. P., Casamitjana, X., Assireu, A. T., \& de Moraes Novo, E. M. L. (2010). Remote sensing of water surface temperature and heat flux over a tropical hydroelectric reservoir. Remote Sensing of Environment, 114(11), 2651-2665.

Aslami, F., \& Ghorbani, A. (2018). Object-based land-use/land-cover change detection using Landsat imagery: A case study of Ardabil, Namin, and Nir counties in northwest Iran. Environmental Monitoring and Assessment, 190(7), 1-14.

Baban, S. M. J. (1993). Detecting water quality parameters in the Norfolk Broads UK, using Landsat imagery. International Journal of Remote Sensing. https://doi.org/10.1080/ 01431169308953955

Bäckström, M., Börjesson, E., \& Karlsson, S. (2002). Diurnal variations of abiotic parameters in a stream, recipient for drainage water in Ranstad, southwest Sweden. Journal of Environmental Monitoring, 4(5), 772-777.

Barsi, J. A., Schott, J. R., Hook, S. J., Raqueno, N. G., Markham, B. L., \& Radocinski, R. G. (2014). Landsat-8 thermal infrared sensor (TIRS) vicarious radiometric calibration. Remote Sensing, 6(11), 11607-11626.

Behera, M. D., Gupta, A. K., Barik, S. K., Das, P., \& Panda, R. M. (2018). Use of satellite remote sensing as a monitoring tool for land and water resources development activities in an Indian tropical site. Environmental Monitoring and Assessment, 190(7), $1-21$.

Beschta,R.L. (1997). Riparian Shade and Stream Temperature: An Alternative Perspective. Rangelands, https://www.jstor.org/ stable/4001341.

Bharati, L., Lacombe, G., Gurung, P., Jayakody, P., Hoanh, C. T., \& Smakhtin, V. (2011). The impacts of water infrastructure and 
climate change on the hydrology of the Upper Ganges River Basin (Vol. 142). IWMI.

Brown, G. W., \& Krygier, J. T. (1970). Effects of clear-cutting on stream temperature. Water Resources Research. https://doi.org/ 10.1029/WR006i004p01133

Caissie, D. (2006). The thermal regime of rivers: A review. Freshwater Biology. https://doi.org/10.1111/j.1365-2427.2006. 01597.x

Carpenter, S. R., Fisher, S. G., Grimm, N. B., \& Kitchell, J. F. (1992). Global change and freshwater ecosystems. Annual Review of Ecology and Systematics, 23(1), 119-139.

Cherkauer, K. A., Burges, S. J., Handcock, R. N., Kay, J. E., Kampf, S. K., \& Gillespie, A. R. (2005). Assessing satellite-based and aircraft-based thermal infrared remote sensing for monitoring pacific northwest river temperature. Journal of the American Water Resources Association, 41(5), 1149-1159.

Clark, M. E., Rose, K. A., Levine, D. A., \& Hargrove, W. W. (2001). Predicting climate change effects on Appalachian trout: Combining GIS and individual-based modeling. Ecological Applications, 11(1), 161-178.

Crisp, D. T. (1990). Water temperature in a stream gravel bed and implications for salmonid incubation. Freshwater Biology. https://doi.org/10.1111/j.1365-2427.1990.tb00298.x

Cristea, N. C., \& Burges, S. J. (2009). Use of thermal infrared imagery to complement monitoring and modeling of spatial stream temperatures. Journal of Hydrologic Engineering. https:// doi.org/10.1061/(ASCE)HE.1943-5584.0000072

Dadgar, M. A., Zeaieanfirouzabadi, P., Dashti, M., \& Porhemmat, R. (2017). Extracting of prospective groundwater potential zones using remote sensing data, GIS, and a probabilistic approach in Bojnourd basin, NE of Iran. Arabian Journal of Geosciences, 10(5), 114.

Daigavane, V. V., \& Gaikwad, M. A. (2017). Water quality monitoring system based on IoT. Department Electronics and Telecommunication Engineering. Advances in Wireless and Mobile Communications, 10(5), 1107-1116.

Das, N., Kumar, V., Tewari, A., Agnihotri, A. K., Gaur, S., \& Ohri, A. (2019). Periodic Monitoring of Rivers Using Portable Sensor System. In 2019 8th International Conference System Modeling and Advancement in Research Trends (SMART) IEEE, https:// doi.org/10.1109/SMART46866.2019.9117555.

Das, N., Bhattacharjee, R., Choubey, A., Ohri, A., Dwivedi, S. B., \& Gaur, S. (2021). Time series analysis of automated surface water extraction and thermal pattern variation over the Betwa river, India. Advances in Space Research, 68(4), 1761-1788.

Das, N., Ohri, A., Agnihotri, A. K., Omar, P. J., \& Mishra, S. (2020). Wetland dynamics using geo-spatial technology. Advances in Water Resources Engineering and Management, 39, 237-244. https://doi.org/10.1007/978-981-13-8181-2_18

Dash, P., Göttsche, F. M., Olesen, F. S., \& Fischer, H. (2002). Land surface temperature and emissivity estimation from passive sensor data: Theory and practice-current trends. International Journal of Remote Sensing, 23(13), 2563-2594.

Eaton, J. G., McCormick, J. H., Goodno, B. E., O'brien, D. G., Stefany, H. G., Hondzo, M., \& Scheller, R. M. (1995a). A field information-based system for estimating fish temperature tolerances. Fisheries, 20(4), 10-18.

Eaton, J. G., McCormick, J. H., Stefan, H. G., \& Hondzo, M. (1995b). Extreme value analysis of a fish/temperature field database. Ecological Engineering, 4(4), 289-305.

Fatemi, M., \& Narangifard, M. (2019). Monitoring LULC changes and its impact on the LST and NDVI in District 1 of Shiraz City. Arabian Journal of Geosciences, 12(4), 1-12.

Flebbe, P. A., Roghair, L. D., \& Bruggink, J. L. (2006). Spatial modeling to project southern Appalachian trout distribution in a warmer climate. Transactions of the American Fisheries Society, 135(5), 1371-1382.

Frazier, P. S., \& Page, K. J. (2000). Water body detection and delineation with Landsat TM data. Photogrammetric Engineering and Remote Sensing, 66(12), 1461-1468.

Garg, V., Aggarwal, S. P., \& Chauhan, P. (2020). Changes in turbidity along Ganga River using Sentinel-2 satellite data during lockdown associated with COVID-19. Geomatics, Natural Hazards and Risk, 11(1), 1175-1195.

Gautam, V. K., Gaurav, P. K., Murugan, P., \& Annadurai, M. (2015). Assessment of surface water Dynamicsin Bangalore using WRI, NDWI, MNDWI, supervised classification and KT transformation. Aquatic Procedia, 4, 739-746.

Ghosh, S., Das, A., Hembram, T. K., Saha, S., Pradhan, B., \& Alamri, A. M. (2020). Impact of COVID-19 induced lockdown on environmental quality in four Indian megacities using Landsat 8 OLI and TIRS-derived data and Mamdani fuzzy logic modelling approach. Sustainability, 12(13), 5464.

Gibson, R. J. (1966). Some factors influencing the distributions of brook trout and young Atlantic salmon. Journal of the Fisheries Board of Canada, 23(12), 1977-1980.

Handcock, R. N., Gillespie, A. R., Cherkauer, K. A., Kay, J. E., Burges, S. J., \& Kampf, S. K. (2006). Accuracy and uncertainty of thermalinfrared remote sensing of stream temperatures at multiple spatial scales. Remote Sensing of Environment, 100(4), 427-440.

Hogg, I. D., \& Williams, D. D. (1996). Response of stream invertebrates to a global-warming thermal regime: An ecosystem-level manipulation. Ecology, 77(2), 395-407.

Jain, C. K., \& Singh, S. (2020). Impact of climate change on the hydrological dynamics of River Ganga, India. Journal of Water and Climate Change, 11(1), 274-290.

Kay, J. E., Kampf, S. K., Handcock, R. N., Cherkauer, K. A., Gillespie, A. R., \& Burges, S. J. (2005). Accuracy of lake and stream temperatures estimated from thermal infrared images. Journal of the American Water Resources Association, 41(5), 1161-1175.

Kumar, S., Jha, P., Baier, K., Jha, R., \& Azzam, R. (2012). Pollution of Ganga river due to urbanization of Varanasi: Adverse conditions faced by the slum population. Environment and Urbanization Asia, 3(2), 343-352.

Kumar, V., Sharma, A., Chawla, A., Bhardwaj, R., \& Thukral, A. K. (2016). Water quality assessment of river Beas, India, using multivariate and remote sensing techniques. Environmental Monitoring and Assessment, 188(3), 137.

Lamaro, A. A., Mariñelarena, A., Torrusio, S. E., \& Sala, S. E. (2013). Water surface temperature estimation from Landsat 7 ETM+ thermal infrared data using the generalized singlechannel method: Case study of Embalse del Río Tercero (Córdoba, Argentina). Advances in Space Research, 51(3), 492-500.

Ling, F., Foody, G. M., Du, H., Ban, X., Li, X., Zhang, Y., \& Du, Y. (2017). Monitoring thermal pollution in rivers downstream of dams with Landsat ETM+ thermal infrared images. Remote Sensing, 9(11), 1175.

Loperfido, J. V., Just, C. L., \& Schnoor, J. L. (2009). High-frequency diel dissolved oxygen stream data modeled for variable temperature and scale. Journal of Environmental Engineering, 135(12), 1250-1256.

Magoulick, D. D., \& Kobza, R. M. (2003). The role of refugia for fishes during drought: A review and synthesis. Freshwater Biology, 48(7), 1186-1198.

Mahato, S., Pal, S., \& Ghosh, K. G. (2020). Effect of lockdown amid COVID-19 pandemic on air quality of the megacity Delhi, India. Science of the Total Environment, 730, 139086.

Mertes, L. A., Smith, M. O., \& Adams, J. B. (1993). Estimating suspended sediment concentrations in surface waters of the 
Amazon River wetlands from Landsat images. Remote Sensing of Environment, 43(3), 281-301.

Mi, H., Qiao, G., Wang, W., \& Hong, Y. (2019). Analysis of urban growth from 1960 to 2015 using historical DISP and Landsat time series data in Shanghai. Arabian Journal of Geosciences, 12(7), $1-16$

Mishra, A., \& Tripathi, B. D. (2008). Heavy metal contamination of soil, and bioaccumulation in vegetables irrigated with treated waste water in the tropical city of Varanasi, India. Toxicological and Environmental Chemistry, 90(5), 861-871.

Mishra, S., Singh, A. L., \& Tiwary, D. (2014). Studies of physicochemical status of the ponds at Varanasi Holy City under Anthropogenic influences. International Journal of Environmental Research and Development, 4(3), 261-268.

Mohseni, O., Stefan, H. G., \& Eaton, J. G. (2003). Global warming and potential changes in fish habitat in US streams. Climatic Change, 59(3), 389-409.

Montanaro, M., Levy, R., \& Markham, B. (2014). On-orbit radiometric performance of the Landsat 8 Thermal Infrared Sensor. Remote Sensing, 6(12), 11753-11769.

Morse, W. L. (1972). Stream temperature prediction under reduced flow. Journal of the Hydraulics Division, 98(6), 1031-1047.

Mosley, M. P. (1983). Variability of water temperatures in the braided Ashley and Rakaia rivers. New Zealand Journal of Marine and Freshwater Research, 17(3), 331-342.

Nandi, I., Srivastava, P. K., \& Shah, K. (2017). Floodplain mapping through support vector machine and optical/infrared images from Landsat 8 OLI/TIRS sensors: Case study from Varanasi. Water Resources Management, 31(4), 1157-1171.

Novo, E. M. L., de Farias Barbosa, C. C., de Freitas, R. M., Shimabukuro, Y. E., Melack, J. M., \& Pereira Filho, W. (2006). Seasonal changes in chlorophyll distributions in Amazon floodplain lakes derived from MODIS images. Limnology, 7(3), 153-161.

Null, S. E., Mouzon, N. R., \& Elmore, L. R. (2017). Dissolved oxygen, stream temperature, and fish habitat response to environmental water purchases. Journal of Environmental Management, 197, 559-570.

Osgouei, P. E., \& Kaya, S. (2017). Analysis of land cover/use changes using Landsat 5 TM data and indices. Environmental Monitoring and Assessment, 189(4), 136.

Pandey, J., \& Singh, R. (2017). Heavy metals in sediments of Ganga River: Up-and downstream urban influences. Applied Water Science, 7(4), 1669-1678.

Poole, G. C., \& Berman, C. H. (2001). An ecological perspective on in-stream temperature: Natural heat dynamics and mechanisms of human-caused thermal degradation. Environmental Management, 27(6), 787-802.

Rai, P. K., Mishra, A., \& Tripathi, B. D. (2010). Heavy metal and microbial pollution of the River Ganga: A case study of water quality at Varanasi. Aquatic Ecosystem Health and Management, 13(4), 352-361.

Rai, P. K., \& Tripathi, B. D. (2008). Heavy metals in industrial wastewater, soil and vegetables in Lohta village, India. Toxicological and Environmental Chemistry, 90(2), 247-257.

Rajeshwari, A., \& Mani, N. D. (2014). Estimation of land surface temperature of Dindigul district using Landsat 8 data. International Journal of Research in Engineering and Technology, 3(5), 122-126.

Reuter, D. C., Richardson, C. M., Pellerano, F. A., Irons, J. R., Allen, R. G., Anderson, M., et al. (2015). The thermal infrared sensor (TIRS) on landsat 8: Design overview and pre-launch characterization. Remote Sensing, 7(1), 1135-1153.

Richards, D. C., Lester, G., Pfeiffer, J., \& Pappani, J. (2018). Temperature threshold models for benthic macroinvertebrates in
Idaho wadeable streams and neighboring ecoregions. Environmental Monitoring and Assessment, 190(3), 1-32.

Rodriguez-Galiano, V., Pardo-Igúzquiza, E., Sanchez-Castillo, M., Chica-Olmo, M., \& Chica-Rivas, M. (2012). Downscaling Landsat 7 ETM+ thermal imagery using land surface temperature and NDVI images. International Journal of Applied Earth Observation and Geoinformation, 18, 515-527.

Sarp, G., \& Ozcelik, M. (2017). Water body extraction and change detection using time series: A case study of Lake Burdur, Turkey. Journal of Taibah University for Science, 11(3), 381-391.

Schindler, D. W. (2001). The cumulative effects of climate warming and other human stresses on Canadian freshwaters in the new millennium. Canadian Journal of Fisheries and Aquatic Sciences. https://doi.org/10.1139/f00-179

Schneider, K., \& Mauser, W. (1996). Processing and accuracy of landsat thematic mapper data for lake surface temperature measurement. International Journal of Remote Sensing, 17(11), 2027-2041.

Simon, R. N., Tormos, T., \& Danis, P. A. (2014). Retrieving water surface temperature from archive LANDSAT thermal infrared data: Application of the mono-channel atmospheric correction algorithm over two freshwater reservoirs. International Journal of Applied Earth Observation and Geoinformation, 30, 247-250.

Singh, I. B. (1996). Geological evolution of Ganga plain-an overview. Journal of the Palaeontological Society of India, 41, 99-137.

Sinokrot, B. A., \& Gulliver, J. S. (2000). In-stream flow impact on river water temperatures. Journal of Hydraulic Research. https:// doi.org/10.1080/00221680009498315

Sinokrot, B. A., Stefan, H. G., McCormick, J. H., \& Eaton, J. G. (1995). Modeling of climate change effects on stream temperatures and fish habitats below dams and near groundwater inputs. Climatic Change, 30(2), 181-200.

Smith, K. (2008). River water temperatures: An environmental review. Scottish Geographical Magazine. https://doi.org/10. 1080/00369227208736229

Terzi, E., \& Verep, B. (2011). Effects of water hardness and temperature on the acute toxicity of mercuric chloride on rainbow trout (Oncorhynchus mykiss). Toxicology and Industrial Health. https://doi.org/10.1177/0748233711416943

Torgersen, C. E., Faux, R. N., McIntosh, B. A., Poage, N. J., \& Norton, D. J. (2001). Airborne thermal remote sensing for water temperature assessment in rivers and streams. Remote Sensing of Environment, 76(3), 386-398.

Vannote, R. L., Minshall, G. W., Cummins, K. W., Sedell, J. R., \& Cushing, C. E. (1980). The river continuum concept. Canadian Journal of Fisheries and Aquatic Sciences, 37(1), 130-137. https://doi.org/10.1139/f80-017.

Viswanathan, V. C., Molson, J., \& Schirmer, M. (2015). Does river restoration affect diurnal and seasonal changes to surface water quality? A study along the Thur River, Switzerland. Science of the Total Environment, 532, 91-102.

Wawrzyniak, V., Piégay, H., \& Poirel, A. (2012). Longitudinal and temporal thermal patterns of the French Rhône River using Landsat ETM+ thermal infrared images. Aquatic Sciences, 74(3), 405-414.

Webb, B. W. (1996). Trends in stream and river temperature. Hydrological Processes, 10(2), 205-226.

Xin, Z., \& Kinouchi, T. (2013). Analysis of stream temperature and heat budget in an urban river under strong anthropogenic influences. Journal of Hydrology, 489, 16-25.

Publisher's Note Springer Nature remains neutral with regard to jurisdictional claims in published maps and institutional affiliations. 